\title{
T Cell Immunotherapy for Immune Reconstitution and GVHD Prevention After Allogeneic Hematopoietic Stem Cell Transplantation
}

\author{
Barbarella Lucarelli ${ }^{1}$ Pietro Merli $^{1} \cdot$ Luisa Strocchio $^{1} \cdot$ Maria Giuseppina Cefalo $^{1}$ • \\ Letizia Pomponia Brescia $^{1}$ - Franco Locatelli ${ }^{1,2}$
}

Published online: 21 September 2015

(C) Springer International Publishing AG 2015

\begin{abstract}
Many different studies have demonstrated that early recovery of the adaptive immune system after allogeneic hematopoietic stem cell transplantation (HSCT) is predominantly sustained by peripheral expansion of donor-derived, mature lymphocytes transferred with the graft. Different approaches based on the infusion of donor T cells after HSCT have been developed mainly to accelerate immune recovery and to treat/prevent (a) malignancy recurrence, (b) lifethreatening infections, and (c) immune-mediated disorders, such as graft-versus-host disease (GVHD). For many years, donor lymphocyte infusion (DLI) has been a widely used approach to prevent and to treat leukemia recurrence, to convert mixed chimerism into complete donor chimerism, and to accelerate immune reconstitution of patients after HSCT. More sophisticated strategies of adoptive infusion of $\mathrm{T}$ cell
\end{abstract}

This article is part of the Topical Collection on Cellular Therapies: Preclinical and Clinical

\section{Franco Locatelli \\ franco.locatelli@opbg.net \\ Barbarella Lucarelli \\ barbarella.lucarelli@opbg.net \\ Pietro Merli \\ pietro.merli@opbg.net \\ Luisa Strocchio \\ luisa.strocchio@opbg.net \\ Maria Giuseppina Cefalo \\ mpiacefalo@gmail.com \\ Letizia Pomponia Brescia \\ letizia.brescia@opbg.net}

1 Department of Pediatric Hematology-Oncology, IRCCS, Bambino Gesù Children's Hospital, Piazza Sant'Onofrio, 4-00165 Rome, Italy

2 Department of Pediatrics, University of Pavia, Pavia, Italy lines/clones capable of mediating a graft-versus-leukemia (GVL) response, while avoiding GVHD occurrence, or specific for the most life-threatening pathogens (e.g., cytomegalovirus, Epstein-Barr virus, and adenovirus) have been envisaged and successfully tested in pilot trials in the early posttransplantation period. Also, ex vivo expanded regulatory $\mathrm{T}$ (Treg) cells have been shown to be beneficial for preventing GVHD post-HSCT. In this review, we will focus on DLI as well as more complex cellular therapies that require extensive cell manipulation.

Keywords Tcell $\cdot$ Immunotherapy $\cdot$ Immune reconstitution · Hematopoietic stem cell transplantation .

Donor lymphocytes infusions

\section{Introduction}

Hematopoietic stem cell transplantation (HSCT) is the only curative option for a number of both malignant (e.g., acute and chronic leukemia, lymphoma, myelodysplastic syndrome) and non-malignant disorders (e.g., bone marrow failure syndromes, inborn errors of metabolism, immune deficiencies, and hemoglobinopathies) [1]. In all of these settings, both in children and adult patients, immune reconstitution is critical for a favorable outcome [2•], being associated with posttransplant infections [3], graft-versus-host disease (GVHD) [4] (both affecting transplant-related mortality (TRM) [5]), and, in the malignant setting, relapse incidence [6]. Correlations with clinical outcomes have been described for both specific (e.g., CD4+ T cells, regulatory $\mathrm{T}$ (Treg) cells) $[5,7]$ and non-specific (such as total lymphocyte count) [4] cell populations. Moreover, as expected, the interplay between immune reconstitution and transplantation outcomes has been 
demonstrated in all types of HSCT, from HLA-identical to partially matched HSCT [2•].

For all these reasons, strategies aimed at enhancing/ accelerating immune reconstitution in order to (i) reinforce immune competence against pathogens and tumor cells and/ or (ii) modulate donor $\mathrm{T}$ cell alloreactivity appear to be particularly desirable [8]. In this regard, while T cell immunotherapy currently represents the most attractive approach, the separation of GVHD from graft-versus-tumor/graft-versus-infection effect is particularly challenging. This review will provide an overview of the most widely used strategies aimed at enhancing post-transplant immune reconstitution by means of $\mathrm{T}$ lymphocyte administration, focusing on both the simplest and most widely used method, based on the infusion of unmodified donor T cells, and on more sophisticated approaches, based on selection/generation/expansion of specific $\mathrm{T}$ cell subsets.

\section{Donor Lymphocyte Infusion}

Donor lymphocyte infusion (DLI) represents the easiest (and thus most used) strategy to enhance immune reconstitution after HSCT. However, it is well known that the infusion of unmanipulated donor-derived lymphocytes carries the risk of provoking GVHD (or to worsening already present GVHD), thus increasing morbidity and mortality and compromising the beneficial effect of adoptive donor $\mathrm{T}$ cell transfer to the recipient. Several factors determine whether the infusion of donor T lymphocytes will cause GVHD [9], among others, (1) the intensity of the conditioning regimen, (2) the use of in vivo T cell depletion (TCD) with anti-thymocyte globulin or other approaches, (3) the timing of DLI after allogeneic HSCT, (4) the dose of T cells infused, (5) the degree of HLA disparity in the donor-recipient, pair, (6) the type of disease for which HSCT is performed, (7) the ongoing administration of immune suppressive drugs, and (8) the level of donor chimerism at the time of DLI (Fig. 1).

In particular, since the more intensive the conditioning regimen, the more severe is the cytokine storm (and thus the higher the risk of GVHD), delaying the administration of donor lymphocytes after resolution of tissue damage (and the cytokine storm) may not only delay but also prevent/reduce acute GVHD after T-cell-depleted transplant [9].

Treatment of either overt or incipient disease relapse (or a condition of donor-recipient mixed chimerism) after HSCT represents the main indication for performing DLI [10]. In this regard, although DLIs have been used in almost all malignant diseases for which allogeneic HSCT is performed (specifically, chronic myelogenous leukemia (CML) [11], acute myeloid leukemia (AML) [12], juvenile myelomonocytic leukemia (JMML) [13], acute lymphoblastic leukemia (ALL) [14], Hodgkin lymphoma (HL) [15], non-Hodgkin lymphoma

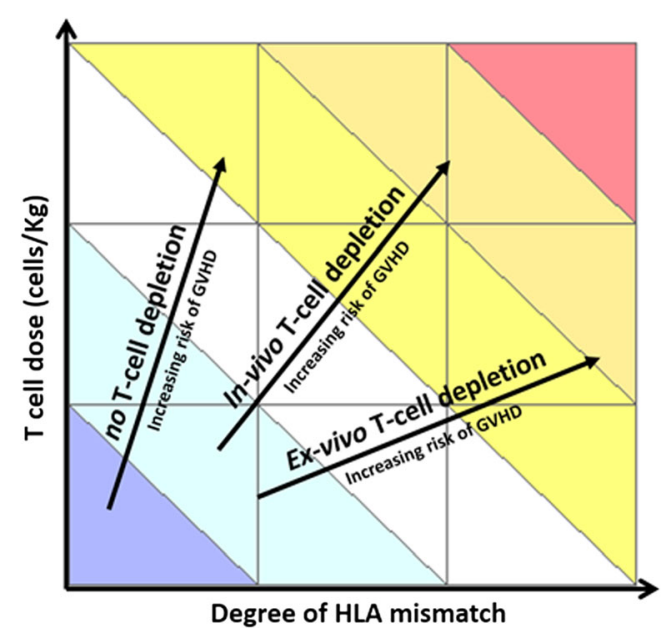

Fig. 1 Relation between T cell dose, grade of donor-recipient HLA mismatch, graft manipulation, and risk of GVHD onset after DLIs

(NHL) [16], multiple myeloma (MM) [17]), CML represents the most consistently successful therapeutic model of this kind of approach. Several studies have reported, in large series of patients treated, response rates after CML relapse as high as $70 \%[11,18,19]$. The experience with DLI in CML has led to a better comprehension of the role of this approach. Although the optimal cell dose remains undefined, some concepts are well established, namely (i) the response is dose dependent; (ii) higher doses increase the risk of developing GVHD; (iii) in recipients of HSCT from a matched unrelated donor (MUD), lower doses are sufficient to obtain the same therapeutic effect as in HLA-identical sibling HSCT; (iv) the best responses are obtained in patients with low tumor burden, such as either molecular or cytogenetic relapse of CML; and (v) there is a higher probability of response in patients relapsing late after transplantation.

DLI has also been used in other hematologic malignancies, such as AML, ALL, NHL, and MM [20]: however, less satisfactory results have been obtained in these diseases. In general, however, the more indolent disorders (such as MM and some type of NHL) seem to respond better to DLI than does acute leukemia.

In almost all of these studies, DLIs were used with a therapeutic purpose (tDLIs) aimed at treating disease relapse, either molecular, cytogenetic, or hematologic. A different approach is the prophylactic administration of donor T cells with a pre-emptive intent (pDLIs), namely before disease relapse, to prevent the occurrence of life-threatening infections. This strategy has been adopted mainly after myeloablative, in vivo, or ex vivo T-cell-depleted HSCT [21-26]. In the largest series reported to date by Montero et al., 112 patients with hematologic malignancies received DLIs containing $10 \times 10^{6} \mathrm{~T}$ cells/ $\mathrm{kg}$ recipient body weight between day +45 and day +100 after T-cell-depleted peripheral blood stem cell transplantation (PBSCT) from an HLA-identical sibling donor [24]. With a median follow-up of 4 years, relapse incidence (RI), TRM, 
and disease-free survival (DFS) were 40,20 , and $46 \%$, respectively, with a cumulative incidence of grades III-IV acute and extensive chronic GVHD of 15 and $25 \%$, respectively. Of note, chronic GVHD was associated with lower overall mortality rate, due to a protective effect on disease recurrence [24].

In an interesting prospective study, Schaap and colleagues treated with DLI 31 patients with high-risk malignant disease at a median time of 22 weeks after partial T-cell-depleted bone marrow transplantation (BMT) from an HLA-identical sibling and compared their outcomes with those of 47 matched patients who did not receive DLI due to the previous onset of acute and/or chronic GVHD [25]. In comparison to the matched controls, patients receiving DLI experienced a statistically significant lower risk of relapse (18 versus $44 \%$, respectively) which resulted in an improved 3-year DFS (77 versus $45 \%$, respectively).

With the aim of optimizing $T$ cell function and/or avoiding excessive alloreactivity, associated with "conventional" DLI, several approaches have been explored; they include the following:

- CD8-depleted DLIs [27-30]; conversely, CD4-depletion does not prevent acute GVHD [31];

- DLIs preventively depleted of the alloreactive component towards recipient tissues either by immunotoxins [32,33] or by photodynamic purging [34];

- Preventive incubation of donor T cells with rapamycin [35];

- Transfection of T cells with suicide genes (see the following section).

Strategies aimed at enhancing $\mathrm{T}$ cell function include the following:

- Treg-depleted DLIs [36];

- Tumor-infiltrating leukocytes [37];

- Ex vivo expanded and activated T cells [38] (e.g., preincubation of $\mathrm{T}$ cells contained in the DLI with cytokines able to augment their function [39]);

- In vivo administration of IL-2 after DLI [40];

- Association with monoclonal antibodies, such as antiCD30 brentuximab vedotin in Hodgkin disease [41].

However, due to the small number of patients treated (and thus the lack of strong evidences of durable clinical effect) and/or the complexity of production methods, which may limit their use to few centers, most of those approaches have not been incorporated into routine clinical practice.

It is interesting to note that use of DLI has been recently reported also in the context of Cord Blood (CB) transplantation [42]. Berglund and coauthors reported nine infusions of ex vivo expanded $\mathrm{CB}$-derived $\mathrm{T}$ cells in four patients because of mixed chimerism, minimal residual disease, or graft failure.
The mean number of cells infused was $1 \times 10^{5} / \mathrm{kg}$; only one patient developed acute GVHD, one patient reversed mixed chimerism, and, in another, control of positive minimal residual disease was achieved.

\section{Genetic Manipulation of Donor T cells with Suicide Genes}

In order to allow the infusion of higher numbers of donorderived T cells also in a haploidentical HSCT setting, strategies based on the use of $\mathrm{T}$ cells engineered with safety switches have been developed [43]. Retro-viral mediated transduction of donor-derived T cells with suicide genes provides a tool to control the risk of acute GVHD in the presence of a high degree of HLA mismatch in the donor-recipient pair (Fig. 1). To date, two different approaches for creating cells with inducible suicide genes have been studied: the San Raffaele group in Milan tested the herpes simplex virus (HSV) thymidine kinase (HSV-TK) gene [44-46], which activated to kill the cell if gancyclovir is administered, and an investigator in Houston tested the use of inducible Caspase 9 (iCasp9) gene, which could be included by administration of the drug AP1503 [47, 48••, 49].

Ciceri and coworkers reported on 50 patients who received haploidentical HSCT after CD34+ cell selection for high-risk leukemia, 28 of whom were treated with HSV-TK-modified T cells starting from 22 days after transplantation at a dose ranging from 0.9 to $40 \times 10^{6} / \mathrm{kg}$ [46]. Ten patients developed grades I-IV acute GVHD and one developed extended chronic GVHD. In all of the patients, the GVHD was controlled by a 14-day course of ganciclovir (plus steroids and cyclosporine A in those patients who had developed the more severe stages of GVHD). Notably, patients obtaining improved immune reconstitution (defined as CD3+ in peripheral blood above 100/ $\mu l$ in two consecutive observations) had a statistically significantly lower probability of non-relapse mortality in comparison with those patients with delayed CD3+ recovery.

Since HSV-TK is potentially immunogenic [50] and exploiting its effect requires a drug, ganciclovir, which remains of significant utility for controlling posttransplantation human cytomegalovirus (CMV) reactivation, Brenner's group in Houston developed a new suicide gene based on the fusion of human caspase 9 to a modified human FK-binding protein (inducible caspase 9, iCasp9). The construct encodes for a protein that dimerizes after exposure to a synthetic inert drug, named AP1903, thus becoming activated and leading to rapid cell death [47]. Zhou and colleagues reported long-term follow-up of 10 patients who received iCasp9 T cell infusion (from $1 \times 10^{6} / \mathrm{kg}$ up to $1 \times 10^{7} / \mathrm{kg}$ ) 30 to 124 days after $\mathrm{CD} 34+$ cell-selected (and thus significantly T cell depleted) haploidentical HSCT [48••]. Investigators found long-term persistence of modified $\mathrm{T}$ cells up to 
24 months after infusion, thus contributing, especially in the earlier phases after HSCT, to immune reconstitution; this was highlighted by evidences of immediate and sustained protection from pathogens like CMV and adenovirus. Four out of the 10 patients developed acute GVHD which was promptly controlled by AP1903 infusion which eliminated $85-95 \%$ of circulating modified T cells within 30 minutes, with no recurrence of GVHD within 90 days. This kinetics of elimination of genetically modified $\mathrm{T}$ cells is much faster than that observed using HSV-TK-modified cells exposed to ganciclovir. It should be noted that virus-specific T cells recovered even after AP1903 administration and continued to provide sustained protection against infections. Noteworthy, both approaches improved immune reconstitution, not only because of the expansion of gene-modified $\mathrm{T}$ cells but also perhaps by accelerating recovery of endogenous (i.e., non-modified) $\mathrm{T}$ cells differentiating from donor hematopoietic stem cells [32, 46, 48••].

A phase I-II study evaluating the safety of iCAsp9 cell infusion in children receiving haploidentical HSCT both for malignant and for non-malignant disorders is currently ongoing at our institution.

\section{Antigen-Specific Cytotoxic T Lymphocytes}

\section{Pathogen-Specific}

After initial proof-of-principle studies on the restoration of immunity against CMV more than 20 years ago by the Seattle group [51, 52], the adoptive transfer of virus-specific $\mathrm{T}$ cells has been developed for many pathogens, especially viruses, including CMV [53], Epstein-Barr virus (EBV) [54], and adenovirus [55], ensuring good clinical results with an acceptable toxicity profile [56]. The techniques developed to obtain $\mathrm{T}$ lymphocytes specific for specified antigens are based on either repeated in vitro exposure of donor lymphocytes to relevant pathogen antigens/peptides followed by cell expansion to obtain larger number of cells to be infused [57], or on a rapid selection procedure based on magnetic-activated cells sorting (MACS) [58], including tetramers [59], streptamer isolation [60], and IFN- $\gamma$ capture [61]. Each of these techniques is discussed below.

\section{Culture Protocols}

Successful ex vivo expansion of virus-specific T (VST) cells requires (i) the identification of the immune-dominant antigens/peptides, (ii) efficient APCs expressing HLA molecules that present virus-derived peptides, (iii) costimulatory signals ensuring $\mathrm{T}$ lymphocyte activation and expansion, and (iv) a prolonged period of culture (the process is time-consuming) [62]. To date, several groups have developed different protocols to improve $\mathrm{T}$ cell function and to reduce the time of the culture as well as the costs and complexity of the process (and thus to develop a widely accessible technique) [53, $63,64]$.

The advantages of these strategies include the small quantity of cells required to start the process (especially compared to other approaches) and the possibility to obtain a broad polyclonal product containing both CD4+ and CD8+ T cells [63]. Moreover, the requirement that donors be seropositive donors to produce/expand specific $\mathrm{T}$ cells has been at least partly solved by the use of in vitro stimulation approaches for antigen-specific stimulation of naive (even CB-derived) T lymphocytes $[65,66]$.

Recent advances in this field include the generation of multi-specific VST cells and the possibility of creating thirdparty VST banks. In a seminal work, Leen and colleagues generated trivirus-specific (i.e., against CMV, EBV, and adenovirus) $\mathrm{T}$ cells from a single culture by preparing antigenpresenting cells (APCs) consisting of activated monocytes and EBV-lymphoblastoid cell lines (LCLs) transduced with an adenoviral vector encoding the immune-dominant CMVpp65 antigen [67]. More recently, this strategy was further improved in terms of complexity, safety, and time required for generation of VSTs [68-70]. It is now possible to rapidly generate single-culture VSTs that recognize 12 immunogenic antigens from five viruses (EBV, adenovirus, $\mathrm{CMV}, \mathrm{BK}$ virus, and human-herpes virus-6, HHV6) [71••]. Another potential breakthrough is the possibility of preparing banks of closely HLA-matched VSTs that can serve as "off the shelf" products, i.e., are available for immediate use. In fact, generating promptly specific VSTs for each individual patient is both impractical and impossible for widespread or urgent use. Despite concerns about safety, several studies have demonstrated the feasibility and efficacy of this approach, without a significant risk of GVHD [72, 73].

\section{Selection by Multimers (Tetramers, Pentamers, and Streptamers)}

These strategies are based on the binding of donor antigenspecific $\mathrm{T}$ cells via the $\mathrm{T}$ cell receptor (TCR) to an antigenspecific multimer (soluble peptide-HLA molecules) coupled with a system that subsequently allows cell selection (e.g., magnetic beads, fluorochrome-streptavidin complexes). This approach was first explored by Cobbold and colleagues who treated nine patients who had CMV reactivation with autologous pathogen-specific T cells selected by tetramers [59]. Although the median cells dose was $8.6 \times 10^{3} / \mathrm{kg}$ (and composed exclusively of CD8+ T cells), the cells expanded in vivo, leading to $\mathrm{CMV}$ viral load clearance in eight out of nine cases.

Since MHC multimer binding may interfere with the functional status of epitope-specific $\mathrm{T}$ cell populations in vivo (e.g., treatment with tetramers can induce epitope-specific 
tolerance in a dose-dependent manner) a different approach is that of streptamer technology. Streptamer technology involves low affinity Strep-tagged MHC molecules that are multimerized with a streptavidin derivative to generate multimers with high binding avidity. Conjugated fluorochromes or magnetic beads are used for cell staining/isolation. Upon addition of d-biotin, which competes with high affinity for the binding of Strep-tag to streptavidin, staining and isolation reagents dissociate rapidly from the cell surface. This reversibility enables multiple cell stainings/sequential positive cell selections. Streptamer technology allows reversible binding and thus does not alter $\mathrm{T}$ cell function or activate $\mathrm{T}$ cells through cross-linking TCRs [74].

The limitations of these techniques are the large starting number of cells needed (i.e., requiring an apheresis procedure), the restriction to HLA alleles for which antigenspecific viral peptides are available, the restriction to viruses for which the donor has detectable circulating $\mathrm{T}$ cells, and the risk of "immune escape" when only one peptide is targeted. For all of these reasons, multimer selection is actually available only for CMV [75], EBV [76], and adenovirus [77].

\section{IFN- $\gamma$ Capture}

Another approach to rapidly selecting VST utilizes IFN- $\gamma$ capture technique, which is based on the ability of Agspecific T cells (both CD4+ and CD8+) to secrete cytokines (IFN- $\gamma$, in particular) after being challenged with antigens. Thus, after short-term (12-16 h) antigen exposure, IFN- $\gamma$ catch reagent is attached to all leukocytes, and, in antigenspecific responding cells, IFN- $\gamma$ remaining attached to the cell surface so that these cells can be subsequently isolated by magnetic selection [78].

The advantages of this strategy are that selected VST cells are both $\mathrm{CD} 4+$ and $\mathrm{CD} 8+$ and that it is not restricted to certain HLA alleles [61]. Again, although the number of VST cells that can be isolated is low, in vivo expansion has been reported to occur and can lead to viral clearance $[79,80]$.

\section{Leukemia-Specific}

Antigen-targeted immunotherapy with ex vivo expanded $\mathrm{T}$ cells is a promising approach to prevent or treat leukemia relapse by enhancing GVL effect, while avoiding GVHD, after allogeneic HSCT, especially in the setting of T-cell depleted HLA-haploidentical HSCT [81]. In this regard, donorderived leukemia-reactive cytotoxic T lymphocytes (CTL) can be generated using as targets either specific antigens (namely tumor-associated antigens (TAAs)) or apoptotic leukemia blasts, in this case providing a broad antigen repertoire. The latter approach was used by Montagna et al. who generated and ex vivo expanded leukemia-reactive CTLs using donor-derived dendritic cells as APCs and apoptotic autologous leukemia blasts as the source of tumor antigen. Donor CTLs have been shown to selectively lyse leukemia blasts, with absent or low-level residual alloreactivity against non-malignant cells [82].

AML cells express several TAAs, which can be targets of ex vivo expanded and adoptively transferred CTLs. The most thoroughly studied leukemia-associated antigens are the Wilms tumor antigen (WT1), proteinase 3 (PR3), human neutrophil elastase (NE), and melanoma-associated antigen. Through in vitro experiments, Weber et al. showed that CTL lines, generated using $15 \mathrm{mer}$ peptide libraries of five TAAs, can target and kill AML cells. Moreover, they were multispecific as assessed by IFN- $\gamma$ enzyme-linked immunospot, regardless of their HLA type [83]. The same authors investigated a similar approach also in the setting of ALL, using WT1, Survivin, MAGE-A3, and PRAME as TAAs [84]. T cell lines were successfully expanded from all patients; moreover, tumor-specific responses were observed by reduction of autologous leukemia blasts in ELISpot, ${ }^{51} \mathrm{Cr}$-release assays, and coculture experiments.

Other possible targets are human minor histocompatibility antigens (mHAgs), which are T cell epitopes derived from polymorphic proteins and presented by various HLA class I and class II molecules. Some human mHAgs are preferentially expressed by leukemia cells, whereas non-hematopoietic tissues do not usually present them. Therefore, hematopoietic system-restricted mHAgs might be exploited to enhance immune responses in GVL, without increasing the risk of GVHD. A phase I clinical trial of adoptive immunotherapy with $\mathrm{T}$ cell clones specific for mHAgs has been reported by Warren and coworkers [85]. CTLs specific for tissue-restricted recipient mHAgs (assessed in in vitro assays) were infused into relapsed patients. Prior to infusion, T cell clones were expanded using culture methods to promote $\mathrm{T}$ cell proliferation and survival. This study showed that the adoptive transfer of mHAgs-specific T cells is able to mediate anti-leukemia activity in vivo, although in some patients treated with high $\mathrm{T}$ cell doses pulmonary toxicity has been observed [85].

\section{Adoptive Transfer of Regulatory T Cells for Prevention of GVHD}

Regulatory $\mathrm{T}$ cells restore tolerance in preclinical models of immune-mediated diseases. Among regulatory $\mathrm{T}$ cells, both $\mathrm{CD} 4+$ and $\mathrm{CD} 8+$ or double negative cells have been described [86]. Within the CD4+ regulatory T cell subsets, the best characterized are the $\mathrm{CD} 4+\mathrm{CD}+\mathrm{FOXP} 3+\mathrm{T}$ regulatory (Treg) cells and the type 1 regulatory $\mathrm{T}(\mathrm{Tr} 1)$ cells. Results from the first clinical trials exploring the adoptive transfer of Tregs in order to prevent GVHD and improve immune reconstitution after allogeneic HSCT are worthy of interest. 
A prerequisite for the clinical use of naturally occurring Treg (nTreg) [86] cells is the ability to efficiently enrich and also expand this rare cell population, ensuring phenotypic homogeneity.

Several strategies have been investigated in order to purify and expand $n$ Treg cells in vitro before infusion or to isolate $\mathrm{nTreg}$ cells in sufficient numbers for in vivo transfer. In the last years, the first trials with CD4+ CD25+ FOXP3+ Treg, either expanded in vitro or freshly isolated, have been reported. The group of Blazer from Minneapolis published the results of a trial of adoptive transfer of expanded third-party CB-derived polyclonal nTreg cells after non-myeloablative unrelated CBT. The adoptively transferred nTregs were present in the peripheral blood of patients up to 14 days after infusion of fresh cells and up to 4 days after the infusion of cryopreserved cells. Compared to identically treated historical controls, in these patients, a reduced incidence of grades II-IV acute GVHD was observed (43 versus $61 \%$ ) without increased risk of opportunistic infections, relapse, or early mortality [87]. However, more recently, the same group reported an increased cumulative incidence of viral reactivation in the early posttransplantation period in patients treated with adoptive transfer of Tregs [88].

In order to obtain a more homogeneous population of Treg cells for clinical application, investigators from Perugia, Italy, explored a different strategy $[89,90]$ in which they infused freshly, immunomagnetically enriched cell separation [91], donor CD4+ CD25+ nTreg cells to adults who were going to be recipients of T-cell-depleted HLAhaploidentical HSCT for hematological malignancies. The adoptive transfer of nTreg cells was followed, 3 days later, by the infusion of CD34+ cells together with a defined dose of donor mature $\mathrm{T}$ cells (conventional $\mathrm{T}$ cells, Tcon), in the absence of any pharmacologic immune suppression. Overall, the immune reconstitution was improved, and high frequencies of CD4+ and CD8+ T cells specific for opportunistic pathogens were detected. This approach demonstrated that the transfer of freshly purified nTreg cells is permissive for infusion of high doses of donor Tcon in the setting of HLA-haploidentical HSCT $[89,90]$.

Adaptive Tr1 cells are defined by their pattern of cytokine production, which include high levels of IL-10 in the absence of IL-4 and low IL-2. Roncarolo and coworkers conducted a phase I-II trial based on the administration of donor-derived IL-10-induced alloantigenspecific Tr1 cells (IL-10-DLI [92]), without immune suppression in patients with high-risk hematological malignancies transplanted with CD34+ cell-selected HLAhaploidentical HSCT. In fact, donor $\mathrm{T}$ cells primed ex vivo with host APCs and IL-10 are anergic towards host-HLA antigens but contain host-specific Tr1 cells and memory $\mathrm{T}$ cells able to respond to pathogens [93]. The five patients treated with this approach showed improved immune reconstitution, and four of them are alive with complete disease remission at 7.2 years (range 6.4-8.3) after HSCT [94, 95], thus providing the first proof-of-concept of feasibility and safety of $\operatorname{Tr} 1$ cellbased therapy and suggesting a clinical benefit of the use of Tr1 cells after HLA-haploidentical HSCT.

Novel approaches to increase Treg potency are actually under investigation. Very recently, the ex vivo fucosylation of third-party human Treg cells has been shown to improve Treg homing to the site of inflammation [96].

\section{Conclusions}

Apart from approaches of graft manipulation [97, 98], T cell therapy techniques represent the best option to enhance immune reconstitution (and thus transplant outcome) after HSCT, especially in high-risk patients (because of disease status or kind of HSCT). In this regard, new therapeutic approaches with gene-modified T cells, with the aim of enhancing effector functions (i.e., chimeric antigen receptors-modified $\mathrm{T}$ cells [99, 100], which, to date, have been rarely employed after HSCT) or of increasing safety through insertion of genes activating $T$ cell apoptosis [47, 49], are particularly promising. Moreover, the possibility of rapid generation of multi-specific VST cells is attractive. The results of the different trials reported are highly encouraging but require confirmation in larger cohorts of patients, homogeneous in terms of disease and treatment, in order to obtain a truly effective comparison among different cell therapy approaches.

However, the real challenge for the future will be the standardization of the manufacturing of these products, together with the spread of these techniques in order to render them widely available, thus improving global transplant outcomes.

Acknowledgments This work was partially supported by grants from AIRC (Associazione Italiana Ricerca sul Cancro, progetto speciale 5xmille), PRIN (Progetti di Rilevante Interesse Nazionale) 2010, MIUR (Ministero dell'Istruzione, Università e della Ricerca), Ministero della Salute (Ricerca Finalizzata 2010), from Regione Lazio, IRCCS Ospedale Pediatrico Bambino Gesù and the HO2020 project "RETHRIM" (\#643580), to F.L.

\section{Compliance with Ethics Guidelines}

Conflict of Interest Barbarella Lucarelli, Pietro Merli, Luisa Strocchio, Maria G. Cefalo, Letizia P. Brescia, and Franco Locatelli declare that they have no conflict of interest.

Human and Animal Rights and Informed Consent This article does not contain any studies with human or animal subjects performed by any of the authors. 


\section{References}

Papers of particular interest, published recently, have been highlighted as:

- Of importance

- Of major importance

1. Copelan EA. Hematopoietic stem-cell transplantation. N Engl J Med. 2006;354(17):1813-26.

2. Bartelink IH, Belitser SV, Knibbe CA, et al. Immune reconstitution kinetics as an early predictor for mortality using various hematopoietic stem cell sources in children. Biol Blood Marrow Transplant. 2013;19(2):305-13. In this study the authors investigated differences in immune reconstitution with different cell sources and the association between the kinetics of immune reconstitution and HSCT outcome.

3. Storek J, Gooley T, Witherspoon RP, et al. Infectious morbidity in long-term survivors of allogeneic marrow transplantation is associated with low CD4 T cell counts. Am J Hematol. 1997;54(2): 131-8.

4. Savani BN, Mielke S, Rezvani K, et al. Absolute lymphocyte count on day 30 is a surrogate for robust hematopoietic recovery and strongly predicts outcome after $\mathrm{T}$ cell-depleted allogeneic stem cell transplantation. Biol Blood Marrow Transplant. 2007;13(10):1216-23.

5. Berger M, Figari O, Bruno B, et al. Lymphocyte subsets recovery following allogeneic bone marrow transplantation (BMT): CD4+ cell count and transplant-related mortality. Bone Marrow Transplant. 2008;41(1):55-62.

6. Parkman R, Cohen G, Carter SL, et al. Successful immune reconstitution decreases leukemic relapse and improves survival in recipients of unrelated cord blood transplantation. Biol Blood Marrow Transplant. 2006;12(9):919-27.

7. Kim DH, Sohn SK, Won DI, et al. Rapid helper T-cell recovery above $200 \times 106 / 1$ at 3 months correlates to successful transplant outcomes after allogeneic stem cell transplantation. Bone Marrow Transplant. 2006;37(12):1119-28.

8. Locatelli F, Giorgiani G, Di-Cesare-Merlone A, et al. The changing role of stem cell transplantation in childhood. Bone Marrow Transplant. 2008;41 Suppl 2:S3-7.

9. Yun HD, Waller EK. Finding the sweet spot for donor lymphocyte infusions. Biol Blood Marrow Transplant. 2013;19(4):507-8.

10. Kolb HJ, Mittermuller J, Clemm C, et al. Donor leukocyte transfusions for treatment of recurrent chronic myelogenous leukemia in marrow transplant patients. Blood. 1990;76(12):2462-5.

11. Simula MP, Marktel S, Fozza C, et al. Response to donor lymphocyte infusions for chronic myeloid leukemia is dose-dependent: the importance of escalating the cell dose to maximize therapeutic efficacy. Leukemia. 2007;21(5):943-8.

12. Schmid C, Labopin M, Nagler A, et al. Donor lymphocyte infusion in the treatment of first hematological relapse after allogeneic stem-cell transplantation in adults with acute myeloid leukemia: a retrospective risk factors analysis and comparison with other strategies by the EBMT Acute Leukemia Working Party. J Clin Oncol. 2007;25(31):4938-45.

13. Yoshimi A, Bader P, Matthes-Martin S, et al. Donor leukocyte infusion after hematopoietic stem cell transplantation in patients with juvenile myelomonocytic leukemia. Leukemia. 2005;19(6): 971-7.

14. Atra A, Millar B, Shepherd V, et al. Donor lymphocyte infusion for childhood acute lymphoblastic leukaemia relapsing after bone marrow transplantation. $\mathrm{Br} \mathrm{J}$ Haematol. 1997;97(1):165-8.
15. De Rosa G, Pezzullo L, Scarpato N, et al. Donor lymphocyte infusion for post-transplant relapse of Hodgkin's lymphoma. Haematologica. 2000;85(7):780-1.

16. Bloor AJ, Thomson K, Chowdhry N, et al. High response rate to donor lymphocyte infusion after allogeneic stem cell transplantation for indolent non-Hodgkin lymphoma. Biol Blood Marrow Transplant. 2008;14(1):50-8.

17. Alyea E, Weller E, Schlossman R, et al. T-cell-depleted allogeneic bone marrow transplantation followed by donor lymphocyte infusion in patients with multiple myeloma: induction of graft-versusmyeloma effect. Blood. 2001;98(4):934-9.

18. Fozza C, Szydlo RM, Abdel-Rehim MM, et al. Factors for graftversus-host disease after donor lymphocyte infusions with an escalating dose regimen: lack of association with cell dose. Br J Haematol. 2007;136(6):833-6.

19. Guglielmi C, Arcese W, Dazzi F, et al. Donor lymphocyte infusion for relapsed chronic myelogenous leukemia: prognostic relevance of the initial cell dose. Blood. 2002;100(2):397-405.

20. Tomblyn M, Lazarus HM. Donor lymphocyte infusions: the long and winding road: how should it be traveled? Bone Marrow Transplant. 2008;42(9):569-79.

21. Barrett AJ, Mavroudis D, Tisdale J, et al. T cell-depleted bone marrow transplantation and delayed $\mathrm{T}$ cell add-back to control acute GVHD and conserve a graft-versus-leukemia effect. Bone Marrow Transplant. 1998;21(6):543-51.

22. Ferra C, Rodriguez-Luaces M, Gallardo D, et al. Individually adjusted prophylactic donor lymphocyte infusions after CD34selected allogeneic peripheral blood stem cell transplantation. Bone Marrow Transplant. 2001;28(10):963-8.

23. Lee CK, de Magalhaes-Silverman M, Hohl RJ, et al. Prophylactic $\mathrm{T}$ cell infusion after $\mathrm{T}$ cell-depleted bone marrow transplantation in patients with refractory lymphoma. Bone Marrow Transplant. 2002;29(7):615-20.

24. Montero A, Savani BN, Shenoy A, et al. T-cell depleted peripheral blood stem cell allotransplantation with T-cell add-back for patients with hematological malignancies: effect of chronic GVHD on outcome. Biol Blood Marrow Transplant. 2006;12(12):1318 25.

25. Schaap N, Schattenberg A, Bar B, et al. Induction of graft-versusleukemia to prevent relapse after partially lymphocyte-depleted allogeneic bone marrow transplantation by pre-emptive donor leukocyte infusions. Leukemia. 2001;15(9):1339-46.

26. de Lima M, Bonamino M, Vasconcelos Z, et al. Prophylactic donor lymphocyte infusions after moderately ablative chemotherapy and stem cell transplantation for hematological malignancies: high remission rate among poor prognosis patients at the expense of graft-versus-host disease. Bone Marrow Transplant. 2001;27(1): 73-8.

27. Dodero A, Carniti C, Raganato A, et al. Haploidentical stem cell transplantation after a reduced-intensity conditioning regimen for the treatment of advanced hematologic malignancies: posttransplantation CD8-depleted donor lymphocyte infusions contribute to improve T-cell recovery. Blood. 2009;113(19):4771-9.

28. Meyer RG, Britten CM, Wehler D, et al. Prophylactic transfer of CD8-depleted donor lymphocytes after T-cell-depleted reducedintensity transplantation. Blood. 2007;109(1):374-82.

29. Shimoni A, Gajewski JA, Donato M, et al. Long-Term follow-up of recipients of CD8-depleted donor lymphocyte infusions for the treatment of chronic myelogenous leukemia relapsing after allogeneic progenitor cell transplantation. Biol Blood Marrow Transplant. 2001;7(10):568-75.

30. Champlin R, Ho W, Gajewski J, et al. Selective depletion of CD8+ $\mathrm{T}$ lymphocytes for prevention of graft-versus-host disease after allogeneic bone marrow transplantation. Blood. 1990;76(2):418 23. 
31. Nagler A, Condiotti R, Nabet C, et al. Selective CD4+ T-cell depletion does not prevent graft-versus-host disease. Transplantation. 1998;66(1):138-41.

32. Amrolia PJ, Muccioli-Casadei G, Huls H, et al. Adoptive immunotherapy with allodepleted donor T-cells improves immune reconstitution after haploidentical stem cell transplantation. Blood. 2006;108(6):1797-808.

33. Andre-Schmutz I, Le Deist F, Hacein-Bey-Abina S, et al. Immune reconstitution without graft-versus-host disease after haemopoietic stem-cell transplantation: a phase $1 / 2$ study. Lancet. 2002;360(9327):130-7.

34. Perruccio K, Topini F, Tosti A, et al. Optimizing a photoallodepletion protocol for adoptive immunotherapy after haploidentical SCT. Bone Marrow Transplant. 2012;47(9):1196-200.

35. Durakovic N, Radojcic V, Powell J, et al. Rapamycin promotes emergence of IL-10-secreting donor lymphocyte infusion-derived $\mathrm{T}$ cells without compromising their graft-versus-leukemia reactivity. Transplantation. 2007;83(5):631-40.

36. Maury S, Lemoine FM, Hicheri Y, et al. CD4+ CD+ regulatory T cell depletion improves the graft-versus-tumor effect of donor lymphocytes after allogeneic hematopoietic stem cell transplantation. Sci Transl Med. 2010;2(41):41ra52.

37. Hardy NM, Fellowes V, Rose JJ, et al. Costimulated tumorinfiltrating lymphocytes are a feasible and safe alternative donor cell therapy for relapse after allogeneic stem cell transplantation. Blood. 2012;119(12):2956-9.

38. Porter DL, Levine BL, Bunin N, et al. A phase 1 trial of donor lymphocyte infusions expanded and activated ex vivo via $\mathrm{CD} 3 /$ CD28 costimulation. Blood. 2006;107(4):1325-31.

39. Slavin S, Naparstek E, Nagler A, et al. Allogeneic cell therapy with donor peripheral blood cells and recombinant human interleukin-2 to treat leukemia relapse after allogeneic bone marrow transplantation. Blood. 1996;87(6):2195-204.

40. Nadal E, Fowler A, Kanfer E, et al. Adjuvant interleukin-2 therapy for patients refractory to donor lymphocyte infusions. Exp Hematol. 2004;32(2):218-23.

41. Theurich S, Malcher J, Wennhold K, et al. Brentuximab vedotin combined with donor lymphocyte infusions for early relapse of Hodgkin lymphoma after allogeneic stem-cell transplantation induces tumor-specific immunity and sustained clinical remission. $\mathrm{J}$ Clin Oncol. 2013;31(5):e59-63.

42. Berglund S, Gertow J, Uhlin M, et al. Expanded umbilical cord blood $\mathrm{T}$ cells used as donor lymphocyte infusions after umbilical cord blood transplantation. Cytotherapy. 2014;16(11):1528-36.

43. Ciceri F, Bonini C, Gallo-Stampino C, et al. Modulation of GvHD by suicide-gene transduced donor T lymphocytes: clinical applications in mismatched transplantation. Cytotherapy. 2005;7(2):144-9.

44. Bonini C, Ferrari G, Verzeletti S, et al. HSV-TK gene transfer into donor lymphocytes for control of allogeneic graft-versus-leukemia. Science. 1997;276(5319):1719-24.

45. Ciceri F, Bonini C, Marktel S, et al. Antitumor effects of HSV-TKengineered donor lymphocytes after allogeneic stem-cell transplantation. Blood. 2007;109(11):4698-707.

46. Ciceri F, Bonini C, Stanghellini MT, et al. Infusion of suicidegene-engineered donor lymphocytes after family haploidentical haemopoietic stem-cell transplantation for leukaemia (the TK007 trial): a non-randomised phase I-II study. Lancet Oncol. 2009;10(5):489-500.

47. Di Stasi A, Tey SK, Dotti G, et al. Inducible apoptosis as a safety switch for adoptive cell therapy. N Engl J Med. 2011;365(18): 1673-83. doi:10.1056/NEJMoa1106152.

48.• Zhou X, Di Stasi A, Tey SK, et al. Long-term outcome after haploidentical stem cell transplant and infusion of T cells expressing the inducible caspase 9 safety transgene. Blood. 2014;123(25): 3895-905. Zhou and colleagues report the long-term follow-up (median 493 days) of 10 patients infused with iC9-transduced
T cells, thus supporting the safety and the beneficial effects of this approach.

49. Zhou X, Dotti G, Krance RA, et al. Inducible caspase-9 suicide gene controls adverse effects from alloreplete $\mathrm{T}$ cells after haploidentical stem cell transplantation. Blood. 2015.

50. Traversari C, Marktel S, Magnani Z, et al. The potential immunogenicity of the TK suicide gene does not prevent full clinical benefit associated with the use of TK-transduced donor lymphocytes in HSCT for hematologic malignancies. Blood. 2007;109(11):4708-15.

51. Riddell SR, Watanabe KS, Goodrich JM, et al. Restoration of viral immunity in immunodeficient humans by the adoptive transfer of T cell clones. Science. 1992;257(5067):238-41.

52. Walter EA, Greenberg PD, Gilbert MJ, et al. Reconstitution of cellular immunity against cytomegalovirus in recipients of allogeneic bone marrow by transfer of T-cell clones from the donor. $\mathrm{N}$ Engl J Med. 1995;333(16):1038-44.

53. Einsele H, Roosnek E, Rufer N, et al. Infusion of cytomegalovirus (CMV)-specific T cells for the treatment of CMV infection not responding to antiviral chemotherapy. Blood. 2002;99(11):3916-22.

54. Rooney CM, Smith CA, Ng CY, et al. Use of gene-modified virusspecific T lymphocytes to control Epstein-Barr-virus-related lymphoproliferation. Lancet. 1995;345(8941):9-13.

55. Comoli P, Basso S, Labirio M, et al. T cell therapy of Epstein-Barr virus and adenovirus infections after hemopoietic stem cell transplant. Blood Cells Mol Dis. 2008;40(1):68-70.

56. Melenhorst JJ, Leen AM, Bollard CM, et al. Allogeneic virusspecific T cells with HLA alloreactivity do not produce GVHD in human subjects. Blood. 2010;116(22):4700-2.

57. Peggs KS, Verfuerth S, Pizzey A, et al. Adoptive cellular therapy for early cytomegalovirus infection after allogeneic stem-cell transplantation with virus-specific T-cell lines. Lancet. 2003;362(9393):1375-7.

58. Manz R, Assenmacher M, Pfluger E, et al. Analysis and sorting of live cells according to secreted molecules, relocated to a cellsurface affinity matrix. Proc Natl Acad Sci U S A. 1995;92(6): 1921-5.

59. Cobbold M, Khan N, Pourgheysari B, et al. Adoptive transfer of cytomegalovirus-specific CTL to stem cell transplant patients after selection by HLA-peptide tetramers. J Exp Med. 2005;202(3): 379-86.

60. Odendahl M, Grigoleit GU, Bonig H, et al. Clinical-scale isolation of 'minimally manipulated' cytomegalovirus-specific donor lymphocytes for the treatment of refractory cytomegalovirus disease. Cytotherapy. 2014;16(9):1245-56.

61. Feuchtinger T, Matthes-Martin S, Richard C, et al. Safe adoptive transfer of virus-specific T-cell immunity for the treatment of systemic adenovirus infection after allogeneic stem cell transplantation. Br J Haematol. 2006;134(1):64-76.

62. Leen AM, Heslop HE, Brenner MK. Antiviral T-cell therapy. Immunol Rev. 2014;258(1):12-29.

63. Perruccio K, Tosti A, Burchielli E, et al. Transferring functional immune responses to pathogens after haploidentical hematopoietic transplantation. Blood. 2005;106(13):4397-406.

64. Heslop HE, Slobod KS, Pule MA, et al. Long-term outcome of EBV-specific T-cell infusions to prevent or treat EBV-related lymphoproliferative disease in transplant recipients. Blood. 2010;115(5):925-35.

65. Hanley PJ, Cruz CR, Savoldo B, et al. Functionally active virusspecific $T$ cells that target CMV, adenovirus, and EBV can be expanded from naive T-cell populations in cord blood and will target a range of viral epitopes. Blood. 2009;114(9):1958-67.

66. Comoli P, Ginevri F, Maccario R, et al. Successful in vitro priming of EBV-specific CD8+ T cells endowed with strong cytotoxic function from $\mathrm{T}$ cells of EBV-seronegative children. Am J Transplant. 2006;6(9):2169-76. 
67. Leen AM, Myers GD, Sili U, et al. Monoculture-derived T lymphocytes specific for multiple viruses expand and produce clinically relevant effects in immunocompromised individuals. Nat Med. 2006;12(10):1160-6.

68. Gerdemann U, Christin AS, Vera JF, et al. Nucleofection of DCs to generate Multivirus-specific T cells for prevention or treatment of viral infections in the immunocompromised host. Mol Ther. 2009;17(9):1616-25.

69. Gerdemann U, Katari UL, Papadopoulou A, et al. Safety and clinical efficacy of rapidly-generated trivirus-directed $\mathrm{T}$ cells as treatment for adenovirus, EBV, and CMV infections after allogeneic hematopoietic stem cell transplant. Mol Ther. 2013;21(11): 2113-21.

70. Vera JF, Brenner LJ, Gerdemann U, et al. Accelerated production of antigen-specific $T$ cells for preclinical and clinical applications using gas-permeable rapid expansion cultureware (G-Rex). J Immunother. 2010;33(3):305-15.

71.• Papadopoulou A, Gerdemann U, Katari UL, et al. Activity of broad-spectrum $\mathrm{T}$ cells as treatment for AdV, EBV, CMV, BKV, and HHV6 infections after HSCT. Sci Transl Med. 2014;6(242): 242ra83. In this work Papadopoulou and colleagues demonstrated the feasibility of rapid generation of single-culture VSTs that recognize 12 immunogenic antigens from five viruses (Epstein-Barr virus, adenovirus, cytomegalovirus, BK virus, and human herpes virus 6 ).

72. Haque T, Wilkie GM, Taylor C, et al. Treatment of Epstein-Barrvirus-positive post-transplantation lymphoproliferative disease with partly HLA-matched allogeneic cytotoxic T cells. Lancet. 2002;360(9331):436-42.

73. Leen AM, Bollard CM, Mendizabal AM, et al. Multicenter study of banked third-party virus-specific $\mathrm{T}$ cells to treat severe viral infections after hematopoietic stem cell transplantation. Blood. 2013;121(26):5113-23.

74. Knabel M, Franz TJ, Schiemann M, et al. Reversible MHC multimer staining for functional isolation of T-cell populations and effective adoptive transfer. Nat Med. 2002;8(6):631-7.

75. Schmitt A, Tonn T, Busch DH, et al. Adoptive transfer and selective reconstitution of streptamer-selected cytomegalovirus-specific CD8+ T cells leads to virus clearance in patients after allogeneic peripheral blood stem cell transplantation. Transfusion. 2011;51(3):591-9.

76. Uhlin M, Okas M, Gertow J, et al. A novel haplo-identical adoptive CTL therapy as a treatment for EBV-associated lymphoma after stem cell transplantation. Cancer Immunol Immunother. 2010;59(3):473-7.

77. Freimuller C, Stemberger J, Artwohl M, et al. Selection of adenovirus-specific and Epstein-Barr virus-specific T cells with major histocompatibility class I streptamers under Good Manufacturing Practice (GMP)-compliant conditions. Cytotherapy. 2015.

78. Feuchtinger T, Lang $\mathrm{P}$, Hamprecht $\mathrm{K}$, et al. Isolation and expansion of human adenovirus-specific CD4+ and CD8+ T cells according to IFN-gamma secretion for adjuvant immunotherapy. Exp Hematol. 2004;32(3):282-9.

79. Di Nardo M, Li Pira G, Amodeo A, et al. Adoptive immunotherapy with antigen-specific T cells during extracorporeal membrane oxygenation (ECMO) for adenovirus-related respiratory failure in a child given haploidentical stem cell transplantation. Pediatr Blood Cancer. 2014;61(2):376-9.

80. Feuchtinger T, Opherk K, Bethge WA, et al. Adoptive transfer of pp 65-specific $\mathrm{T}$ cells for the treatment of chemorefractory cytomegalovirus disease or reactivation after haploidentical and matched unrelated stem cell transplantation. Blood. 2010;116(20):4360-7.

81. Barrett AJ, Le Blanc K. Immunotherapy prospects for acute myeloid leukaemia. Clin Exp Immunol. 2010;161(2):223-32.
82. Montagna D, Maccario R, Locatelli F. Expansion of antileukaemia CTL lines and clones for adoptive cell therapy in paediatric patients given allogeneic haematopoietic stem cell transplantation. Int J Immunogenet. 2008;35(4-5):389-93.

83. Weber G, Gerdemann U, Caruana I, et al. Generation of multileukemia antigen-specific $\mathrm{T}$ cells to enhance the graft-versusleukemia effect after allogeneic stem cell transplant. Leukemia. 2013;27(7):1538-47.

84. Weber G, Caruana I, Rouce RH, et al. Generation of tumor antigen-specific $\mathrm{T}$ cell lines from pediatric patients with acute lymphoblastic leukemia-implications for immunotherapy. Clin Cancer Res. 2013;19(18):5079-91.

85. Warren EH, Fujii N, Akatsuka Y, et al. Therapy of relapsed leukemia after allogeneic hematopoietic cell transplantation with $\mathrm{T}$ cells specific for minor histocompatibility antigens. Blood. 2010;115(19):3869-78.

86. Abbas AK, Benoist C, Bluestone JA, et al. Regulatory T cells: recommendations to simplify the nomenclature. Nat Immunol. 2013;14(4):307-8.

87. Brunstein CG, Miller JS, Cao Q, et al. Infusion of ex vivo expanded $\mathrm{T}$ regulatory cells in adults transplanted with umbilical cord blood: safety profile and detection kinetics. Blood. 2011;117(3): 1061-70.

88. Brunstein CG, Blazar BR, Miller JS, et al. Adoptive transfer of umbilical cord blood-derived regulatory $\mathrm{T}$ cells and early viral reactivation. Biol Blood Marrow Transplant. 2013;19(8):1271-3.

89. Di Ianni M, Falzetti F, Carotti A, et al. Tregs prevent GVHD and promote immune reconstitution in HLA-haploidentical transplantation. Blood. 2011;117(14):3921-8.

90. Martelli MF, Di Ianni M, Ruggeri L, et al. HLA-haploidentical transplantation with regulatory and conventional T-cell adoptive immunotherapy prevents acute leukemia relapse. Blood. 2014;124(4):638-44.

91. Di Ianni M, Falzetti F, Carotti A, et al. Immunoselection and clinical use of T regulatory cells in HLA-haploidentical stem cell transplantation. Best Pract Res Clin Haematol. 2011;24(3):459-66.

92. Gregori S, Tomasoni D, Pacciani V, et al. Differentiation of type 1 $\mathrm{T}$ regulatory cells $(\mathrm{Tr} 1)$ by tolerogenic DC-10 requires the IL-10dependent ILT4/HLA-G pathway. Blood. 2010;116(6):935-44.

93. Roncarolo MG, Gregori S, Lucarelli B, et al. Clinical tolerance in allogeneic hematopoietic stem cell transplantation. Immunol Rev. 2011;241(1):145-63.

94. Bacchetta R, Gregori S, Serafini G, et al. Molecular and functional characterization of alloantigen-specific anergic T-cells suitable for cell therapy. Haematologica. 2010;95(12):2134-43.

95. Bacchetta R, Lucarelli B, Sartirana C, et al. Immunological outcome in haploidentical-HSC transplanted patients treated with IL10-anergized donor T cells. Front Immunol. 2014;5:16.

96. Parmar S, Liu X, Najjar A, et al. Ex vivo fucosylation of thirdparty human regulatory $\mathrm{T}$ cells enhances anti-graft-versus-host disease potency in vivo. Blood. 2015;125(9):1502-6. doi:10. 1182/blood-2014-10-603449.

97. Bertaina A, Merli P, Rutella S, et al. HLA-haploidentical stem cell transplantation after removal of alphabeta $+\mathrm{T}$ and $\mathrm{B}$ cells in children with nonmalignant disorders. Blood. 2014;124(5):822-6.

98. Martelli MF, Di Ianni M, Ruggeri L, et al. "Designed" grafts for HLA-haploidentical stem cell transplantation. Blood. 2014;123(7):967-73.

99. Grupp SA, Kalos M, Barrett D, et al. Chimeric antigen receptormodified T cells for acute lymphoid leukemia. N Engl J Med. 2013;368(16):1509-18.

100. Lee DW, Kochenderfer JN, Stetler-Stevenson M, et al. T cells expressing CD19 chimeric antigen receptors for acute lymphoblastic leukaemia in children and young adults: a phase 1 doseescalation trial. Lancet. 2015;385(9967):517-28. 